\title{
Long-term shifts in abundance of (migratory) crop-feeding and beneficial insect species in northeastern Asia
}

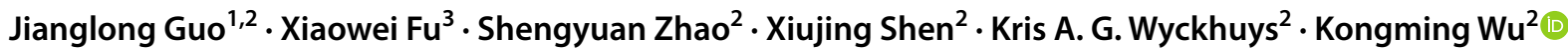

Received: 14 July 2019 / Revised: 16 December 2019 / Accepted: 23 December 2019 / Published online: 3 January 2020

(c) The Author(s) 2020

\begin{abstract}
Vast numbers of insects annually engage in trans-latitudinal migration and thereby impact structure and functioning of natural and man-made ecosystems. In eastern Asia, long-distance migration has historically been studied for single insect species rather than diverse species complexes. Here, we assessed migration dynamics of multiple economically important migratory species on an island in the Bohai Strait, China. Drawing upon 15-year trapping records of $>2.5$ million specimens, we unveil inter- and intra-annual shifts in the species composition and abundance of migrant individuals. Migrants belonged to 9 orders and 36 families, primarily consisting of Lepidoptera (79\% individuals), Odonata (8\%), and Coleoptera (4\%). Seven cropfeeding noctuids, e.g., Helicoverpa armigera (Hübner), Mythimna separata (Walker), represented 54\% of the total trapping records. Trap catches exhibited marked seasonal variation, with the highest capture rate during early fall. Yearly abundance of migratory noctuids was coupled with that of their associated natural enemies. Although overall trap catches did not decrease over the monitoring period, the entire order of Odonata experienced a $14.1 \%$ annual rate of decline. Furthermore, 19 out of 108 species exhibited a progressively declining abundance over time, including the cosmopolitan cutworm Agrotis ipsilon (Hufnagel) and the insectivorous dragonfly Pantala flavescens Fabricius. Our work provides unprecedented insights into insect migration dynamics in eastern Asia, helps fine-tune forecasting and early-warning systems of crop pests, and thereby guides integrated pest management within local agro-landscapes. Also, a long-term tracking of migrant insect populations can shine light on the fate of (insect-mediated) ecosystem services and trophic dynamic processes at a macroscale.
\end{abstract}

Keywords Insect migration $\cdot$ Insect biodiversity $\cdot$ Biodiversity loss $\cdot$ Migratory pests $\cdot$ Aerobiology $\cdot$ Biological control

\section{Key message}

\section{Communicated by M. Traugott.}

Electronic supplementary material The online version of this article (https://doi.org/10.1007/s10340-019-01191-9) contains supplementary material, which is available to authorized users.

Kongming $\mathrm{Wu}$

wukongming@caas.cn

1 College of Plant Protection, Shenyang Agricultural University, Shenyang 110866, China

2 State Key Laboratory for Biology of Plant Diseases and Insect Pests, Institute of Plant Protection, Chinese Academy of Agricultural Sciences, West Yuanmingyuan Road, Beijing 100193, China

3 Department of Plant Protection, Henan Institute of Science and Technology, Xinxiang 453003, China
- Over 2003-2017, we tracked insect migration across China's Bohai Strait and collected migrants belonging to 9 insect orders and 36 families.

- Various insect species, e.g., dragonflies, experienced a progressively declining abundance.

- Yearly abundance of pestiferous noctuids was coupled with that of their associated natural enemies.

- Relative abundance of crop-feeding versus insect-killing species can mirror the strength of ecosystem services, e.g., biological control.

- Our work facilitates (pest) population forecasting and guides area-wide IPM interventions. 


\section{Introduction}

Insect migration is a ubiquitous phenomenon in nature. Every year, vast numbers of insects engage in either diurnal or nocturnal migration-with migrant species belonging to various taxonomic groups, most notably Orthoptera, Lepidoptera, and Hemiptera (Drake and Farrow 1988; Chapman and Drake 2010; Hobson et al. 2012; Chapman et al. 2015; Stefanescu et al. 2017; Early et al. 2018). As an adaptive strategy for survival and reproduction, migration allows insects to escape adverse environmental conditions, natural enemies, or diseases, to track ephemeral resources and to exploit seasonally favorable habitats (Dingle and Drake 2007; Chapman et al. 2011). Long-distance migration further facilitates the annually recurring colonization of agricultural crops by herbivorous species, e.g., the fall armyworm Spodoptera frugiperda (Stokstad 2017).

Aside from involving the large-distance transfer of nutrients, energy or pathogens, insect migration impacts overall ecosystem functioning and sustains the delivery of myriad ecosystem services - often over broad spatial scales (Reynolds et al. 2006; Bauer and Hoye 2014; Hu et al. 2016; Landry et al. 2016). Both insect herbivores and natural enemies engage in long-distance migration, and temporal shifts in their relative abundance can either mitigate or aggravate insect-induced crop damage (Chapman et al. 2011; Cao et al. 2018; Hallworth et al. 2018). Though (long-distance) migration and its associated ecosystem processes are surely affected by the progressive decline in insect abundance, diversity, or biomass (e.g., Hallmann et al. 2017; SanchezBayo and Wyckhuys 2019; Seibold et al. 2019), little or no data exist on such phenomena. Hence, a long-term, systematic assessment of insect migration can help develop and hone strategies to conserve or enhance the delivery of ecosystem services (while reducing disservices, such as pest attack) within both agricultural and natural habitats.

Insect migration is linked to seasonal changes in climate, resource availability and wind patterns (Southwood 1977; Drake and Gatehouse 1995). As such, migration commonly occurs across climatic zones to escape harsh winters in temperate areas, e.g., monarch butterflies (Danaus plexippus L.) undertake multi-generational migration between America and Mexico (Mouritsen and Frost 2002; Flockhart et al. 2013; Chapman et al. 2015). Similarly, the painted lady butterfly Vanessa cardui (Linnaeus) engages in seasonal migration to track and exploit suitable habitats in Africa and Europe (Stefanescu et al. 2013; Talavera and Vila 2016). Insectivorous species such as dragonflies or ladybeetles also exhibit seasonal migration, often in swarms of $>1$ million individuals (Schaefer et al. 1987; Russell et al. 1998).

In northeastern Asia, the middle and warm temperate zones are located between $25^{\circ} \mathrm{N}$ and $50^{\circ} \mathrm{N}$, with local climates typified by brief growing seasons and long winters (Zhang et al. 2017). Both regions contain extensive agricultural areas in which cotton, corn, soybean, and wheat crops provide suitable habitats for various migratory species including herbivorous pests, 'neutral' species, and insectivorous natural enemies. Agricultural pests such as rice planthoppers (Kisimoto 1981; Rutter et al. 1998) or various species of noctuid moths (Chen et al. 1989; Liu et al. 2016; Fu et al. 2017) engage in seasonal-windborne-migration. Specifically, immigrants from the (sub-)tropics initiate their population build-up in the warm temperate zone during spring (Cheng et al. 1979; Drake and Gatehouse 1995). The offspring of these spring colonists then migrate into the middle temperate zone (i.e., summer breeding region) during summer. During fall, adverse environmental conditions and lowering food availability then trigger a return migration of insects. This annually recurring migration represents a remarkable adaptation to local climate, weather, and host availability (Drake and Gatehouse 1995). Although the migration processes of several individual pest species have been well characterized, e.g., using long-term monitoring on China's Beihuang Island (BH) at the intersection of two climatic zones and key agricultural regions, multi-species migration dynamics so far have received scant research attention.

Here, we carried out a multi-year systematic assessment of seasonal migration for multiple taxa of flying insects by using (high-altitude) searchlight trapping at $\mathrm{BH}$. We quantitatively analyze species composition and seasonality of trapped individuals and examine intra- and inter-annual differences in the abundance of individual species, higher taxonomic groupings and separate feeding guilds. Our findings can readily be incorporated into strategies for 'area-wide' pest management (Vreysen et al. 2007) and also mirror the delivery of insect-mediated ecosystem services over extensive geographical areas.

\section{Materials and methods}

\section{Study area and trapping method}

Monitoring work was carried out on $\mathrm{BH}\left(38^{\circ} 24^{\prime} \mathrm{N}\right.$; $120^{\circ} 55^{\prime} \mathrm{E}$ ) in the center of the Bohai Strait, northeastern China. BH has an area of approx. $2.5 \mathrm{~km}^{2}$, has sparse vegetation and no agricultural crops and is located 40-60 km from the nearest (mainland) agricultural regions. A vertical-pointing searchlight trap was deployed at a height of $8 \mathrm{~m}$ above sea level (asl) (Feng et al. 2006), to specifically attract and capture high-altitude migrants of various insect species (up to approx. $500 \mathrm{~m}$ asl) (Feng et al. 2003). The trap was equipped with a $1000-\mathrm{W}$ metal halide lamp (model 
JLZ1000BT; Shanghai Yaming Lighting Co. Ltd., Shanghai, China), which produces a vertical beam of light with a luminous flux of $105,000 \mathrm{~lm}$, a color temperature of $4000 \mathrm{~K}$, and a color rendering index of 65 .

During 2003-2017, the searchlight trap was routinely operated from April to October. The trap was switched on daily from sunset to sunrise-except for times of heavy rain or power outage. A $30 \times 30 \times 40 \mathrm{~cm}$ nylon net bag $(60 \mathrm{mesh})$ was attached beneath the trap to collect field-caught insects. Upon collection, insect samples were kept in a freezer at $-20{ }^{\circ} \mathrm{C}$ for $4 \mathrm{~h}$ before identification. To ascertain that the trapped insects were effectively long-distance migrants and not individuals from BH resident populations, visual observations and sweep net sampling were carried out daily in the immediate vicinity of the trap throughout 2009-2017. Observers searched for larvae or nymphs on any locally occurring plants and assessed the eventual presence of (lateseason) resident insect populations.

\section{Species identification}

Trapped insects were identified to species level by using photographs and reference guides such as Yang (1978), Li and Luo (1979), Zhu et al. (1981, 1982a, b) and Zhou (2001). The few remaining individuals that could not be identified on-site were sent to taxonomists.

\section{Data processing and statistical analysis}

An index of temporal occurrence $(O)$ was calculated by the formula: $O=(p / n) \times 100 \%$, where $p$ represents the number of days a given insect species was trapped during a particular year, and $n$ represents the number of days any species was trapped during that year. Occurrence status was divided into three levels, i.e., infrequent species $(0 \leq O<25 \%)$, frequent species $(25 \leq O<50 \%)$, and regular species $(50 \leq O \leq 100 \%)$ (Serafim et al. 2003). The number of individuals within a specific taxonomic grouping (i.e., order, family, genus)over a particular time window-provided a measure of abundance. To reveal community-level changes in species diversity or richness over time, three indexes were calculated: (1) Shannon-Wiener Diversity Index: $H=-\sum_{i=1}^{s} P_{i} \ln P_{i}$; (2) Margalef Richness Index: $E=(S-1) / \ln N$; and (3) Pielou Evenness Index: $J=H / \ln S$ (Pielou 1966; Zhang et al. 2009). Here, $P_{i}$ represents the ratio of the number of individuals of a given species to the total number of pests or non-pests or total species $\left(n_{i} / N\right)$ at a particular time; $S$ represents the number of pests or non-pests or total species in a given month or year; and $N$ represents the total abundance of pests or non-pests or total species in a given month or year.
To determine a possible quantitative relationship between pests and associated natural enemies, we only considered noctuid pests (i.e., 30 species in the study) and their associated natural enemies (14 species). Here, this choice took account of the following: (1) over the monitoring period, Noctuidae were the most abundant insect family and comprised several crop pests; (2) predatory ladybirds, lacewings, ground beetles, tiger beetles, and multiple species of parasitoids are common natural enemies of noctuids in China's agricultural fields. We equally paid attention to Odonata, being prominent predators of aquatic organisms and flying insects, thus assuming a key role in biological control of, e.g., rice planthoppers (Relyea and Hoverman 2008).

Trapped individuals were sorted to order and family, and their respective annual (and monthly) abundances were calculated. To determine inter-taxa differences in annual abundance, data were subject to a Kruskal-Wallis $H$ test-followed by a Bonferroni-adjusted significance test for pairwise comparisons. To determine seasonal differences in the abundance of total insect species, number of species and community-level diversity indices (i.e., H, E, J), two-way analysis of variance (ANOVA, GLM model) was employed—followed by Tukey's HSD (honestly significant difference) test for pairwise comparisons. In GLM models, month was entered as a fixed effect and year as a random effect. To observe inter-annual trends in the above metrics, linear regression and Pearson correlation analyses were performed, and the correlation coefficient $(r)$ was also calculated. Annual rates of abundance change were calculated from the slope of linear regression. To assess temporal trends in abundance at the species level, we exclusively considered species with total trap catches $>500$ over the 15 -year window and conducted Spearman correlation analysis of their yearly abundance against year. Linear regression analysis was carried out to relate the abundance of noctuid pests and their associated natural enemies over a particular time period. To check the assumptions of normality and homogeneity for parametric analysis, Kolmogorov-Smirnov and Levene's tests were used, respectively. If the raw or transformed data did not meet the above assumptions, nonparametric analysis was used. All statistical analyzes were analyzed by SPSS version 20.0 (IBM Corporation 2011).

\section{Results}

\section{Species composition}

During 2009-2017, no larvae or nymphs of any agriculturally important insect were found on $\mathrm{BH}$ - thus confirming that all trapped individuals were indeed (high-altitude) longdistance migrants from the mainland. Using the searchlight trap, a total of 2,662,174 individuals were collected over 


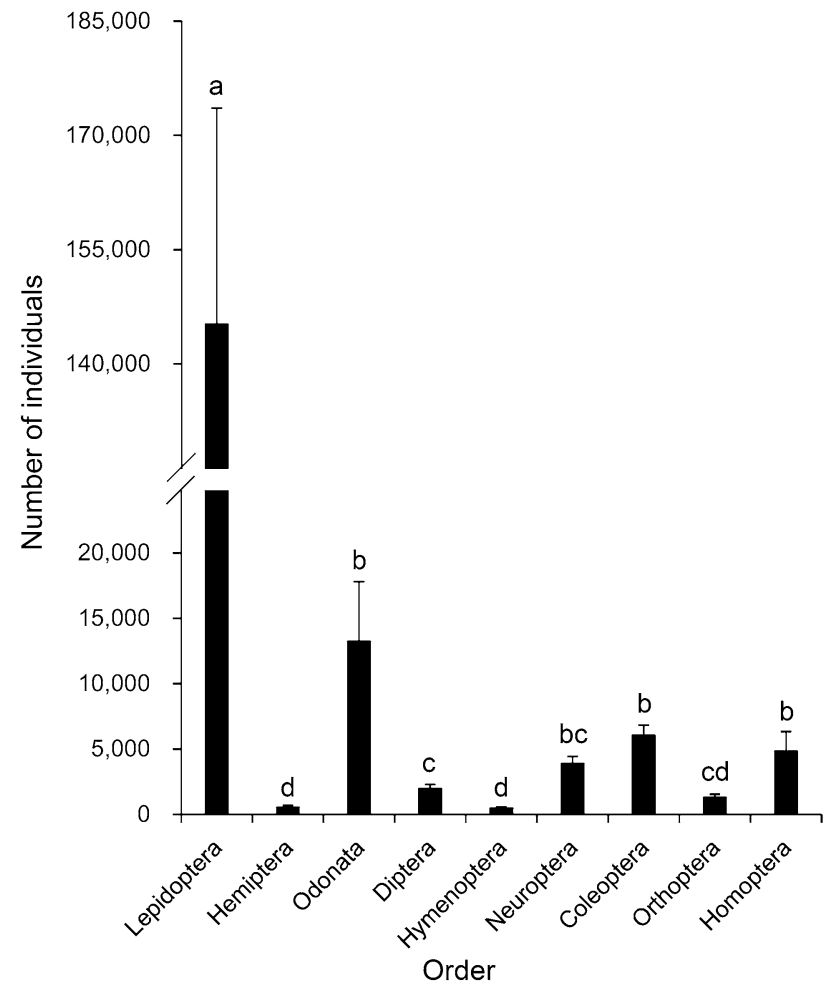

Fig. 1 Taxonomic composition and total abundance of migratory insects captured in (high-altitude) searchlight traps on BH during 2003-2017. Mean annual abundance $( \pm$ SE) is shown for different insect orders, with bars sharing the same letter not exhibiting statistically significant differences in order-level abundance $(P=0.05$; Kruskal-Wallis, Bonferroni-adjusted significance test)

the 15-year period, representing 119 insect species, belonging to 36 families and 9 orders (Fig. 1; Fig. S1). Substantial variability in inter-annual abundance was recorded, with the highest trap catches occurring during 2012 (i.e., 520,007 individuals) (Fig. S2). Mean annual abundance differed significantly between orders (Kruskal-Wallis $H=94.85, P<0.001)$, with Lepidoptera $(145,223 \pm 28,371$ individuals annually; $79.0 \pm 2.7 \%)$ the most abundant taxon, followed by Odonata $(13,231 \pm 4568 ; 7.7 \pm 2.3 \%)$ and Coleoptera $(6036 \pm 799 ; 4.2 \pm 0.7 \%)$ (Fig. 1). Lepidoptera were composed of 10 families and 66 species, with significant family-level variability in mean annual abundance $(H=122.15, P<0.001)$. Noctuidae constituted the most abundant lepidopteran family, at an annual abundance of 111,634 $\pm 28,106$ individuals (Fig. S1a). Odonata contained 3 families and 3 species, with significant family-level variability in mean annual abundance $(H=36.3$, $P<0.001)$; Libellulidae represented the most abundant odonate family $(12,098 \pm 4323$ annually), though included only one species, Pantala flavescens Fabricius (Fig. S1b). Coleoptera contained 9 families and 20 species, with significant family-level variability in mean annual abundance $(H=68.95, P<0.001)$ (Fig. S1b). Three other orders-i.e.,
Diptera, Neuroptera, and Orthoptera-equally exhibited significant family-level variability in mean annual abundance (Diptera: $H=18, P<0.001$; Neuroptera: $H=0, P<0.001$; Orthoptera: $H=26.33, P<0.001$ ) (Fig. S1c). Seven species exhibited a regular occurrence, namely Helicoverpa armigera (Hübner), Mythimna separate (Walker), Agrotis ipsilon (Hufnagel), Agrotis segetum Denis and Schiffermaller, Mamestra brassicae Linnaeus, Protoschinia scutosa (Denis $\&$ Schiffermüller), and Ctenoplusia agnate (Staudinger), representing $9.6 \pm 2.3 \%, 26.1 \pm 6.0 \%, 3.0 \pm 0.5 \%, 1.3 \pm 0.2 \%$, $1.7 \pm 0.2 \%, 0.6 \pm 0.1 \%$, and $5.6 \pm 1.9 \%$ of all catches, respectively. Twenty-five species exhibited frequent occurrence (Table S1).

\section{Seasonal and annual changes}

Monthly abundance was significantly affected by month but not by year (month: $F_{6,84}=7.63, P<0.001$; year: $F_{14,84}=0.96, P=0.50$ ), with a steadily increasing trap capture rate from April to September, followed by a decline up till October (nonlinear model, $y=-0.196 x^{2}+1.824 x+0.417 ; R^{2}=0.93, F_{2,4}=26.15$, $P=0.005$ ) (Fig. 2a). The monthly number of species differed significantly between successive months and years (month: $F_{6,84}=213.27, P<0.001$; year: $F_{14,77}=7.62, P<0.001$ ), with a progressively increasing number of species from April to August, followed by a gradual decrease up till October (nonlinear model, $y=-5.889 x^{2}+51.677 x-37.9$ 37; $R^{2}=0.98, F_{2,4}=112.75, P<0.001$ ) (Fig. 2b). Monthly differences were also recorded in species diversity, richness, and evenness (H: $F_{6,77}=8.241, P<0.001 ; \mathrm{E}: F_{6,77}=99.85$, $\left.P<0.001 ; \mathrm{J}: F_{6,77}=4.98, P<0.001\right)$, but only monthly species richness was affected by year $\left(F_{14,84}=8.41, P<0.001\right)$. Except for species evenness, community-level diversity indices increased over time until July and then decreased (nonlinear model, $\mathrm{H}: y=-0.085 x^{2}+0.763 x+0.891 ; R^{2}=0.75$, $F_{2,4}=21.84, P=0.007 ; \mathrm{E}: y=-0.452 x^{2}+3.906 x-1.465$; $R^{2}=0.99, F_{2,4}=417.79, P<0.001$ ) (Fig. 2 c, d). Over the 15-year period, no significant upward or downward trend was recorded for either diversity index (Pearson's correlation test, number of individuals: pests, $r=-0.06, P=0.85$, non-pests, $r=-0.30, P=0.28$, total, $r=-0.16, P=0.57$; number of species: pests, $r=0.48, P=0.07$, non-pests, $r=0.31, P=0.26$, total, $r=0.45, P=0.09$; species diversity: pests, $r=0.14, P=0.96$, non-pests, $r=-0.31, P=0.26$, total, $r=-0.10, P=0.73$; species richness: pests, $r=0.50$, $P=0.06$, non-pests, $r=0.37, P=0.18$, total, $r=0.45$, $P=0.09$; species evenness: pests, $r=-0.02, P=0.95$, nonpests, $r=-0.32, P=0.24$, total, $r=-0.12, P=0.67$ ) (Fig. 3; Fig. S2).

When assessing temporal patterns of (annual) abundance for all orders and 6 selected families of abundant crop pests or natural enemies, we found that only the annual abundance 



Fig. 2 Seasonal variation in monthly number of individuals (a), number of species (b), species diversity (c), species richness (d) during 2003-2017. Mean monthly values $( \pm$ SE) of the different variables are shown; dots sharing the same letter do not exhibit significant differences at the 0.05 level by Tukey's HSD (hon-

of Odonata and Libellulidae exhibited significant downward trends (Odonata: $r=-0.64, P=0.01$; Libellulidae: $r=-0.61$, $P=0.02$ ), with respective decline rates of $14.1 \%$ and $13.5 \%$ per annum. The yearly abundance of the remaining 8 orders and 5 families did not exhibit any (taxon-specific) directional trends $(P>0.05)$ (Fig. 4; Table S2, S3).

Species-level abundances exhibited clear seasonal differences for multiple taxa. Among the regular species, we recorded fluctuating abundance between successive months with, e.g., 410.0-fold, 2416.0-fold, and 88.6-fold changes in abundance for the crop pests $H$. armigera, $M$. separata, and A. ipsilon, respectively. Given the low and irregular trap catches for 11 species, species-level abundance trends were solely analyzed for 108 species. Over the 15 -year period, annual abundance of most species did not exhibit any directional trend $(P>0.05)$. However, 19 species (e.g., A. ipsilon, $C$. agnata, $P$. flavescens) exhibited a declining abundance, while 3 species (i.e., the cutworm Agrotis tokionis Butler, the yellow peach moth Conogethes punctiferalis Guenée,

estly significant difference) test. Nonlinear model (dashed line): a $y=-0.196 x^{2}+1.824 x+0.417 ; \quad R^{2}=0.93 ; \quad$ b $\quad y=-5.889 x^{2}+51.677$ $x-37.937 ; R^{2}=0.98 ;$ c $y=-0.085 x^{2}+0.763 x+0.891 ; R^{2}=0.74 ;$ d $y=-0.452 x^{2}+3.906 x-1.465 ; R^{2}=0.99$

and the cotton mirid Apolygus lucorum (Meyer-Dür) became more abundant over time $(P<0.05)$ (Table 1$)$.

\section{Noctuid pests and associated natural enemies}

For the 30 species of agriculturally important noctuids, we listed 14 associated natural enemy species belonging to 5 families, i.e., Ichneumonidae, Chrysopidae, Carabidae, Cicindelidae, and Coccinellidae. Mean annual abundance of noctuid pests was higher than that of their associated natural enemies $(t=-12.42, d f=28, P<0.001)$, with respective abundances of $111,767.3 \pm 28,074.0$ and $9422.0 \pm 1042.7$ individuals per year. Also, noctuid pests were recorded earlier than their natural enemies $(t=5.29, P<0.001)$, with the former migrating from early April onward as compared to late April for the latter (Fig. 5). Monthly catches of both functional groups exhibited a consistent annual trend with a peak in late summer (August or September) (Fig. 5), and monthly catches of noctuid pests were positively 

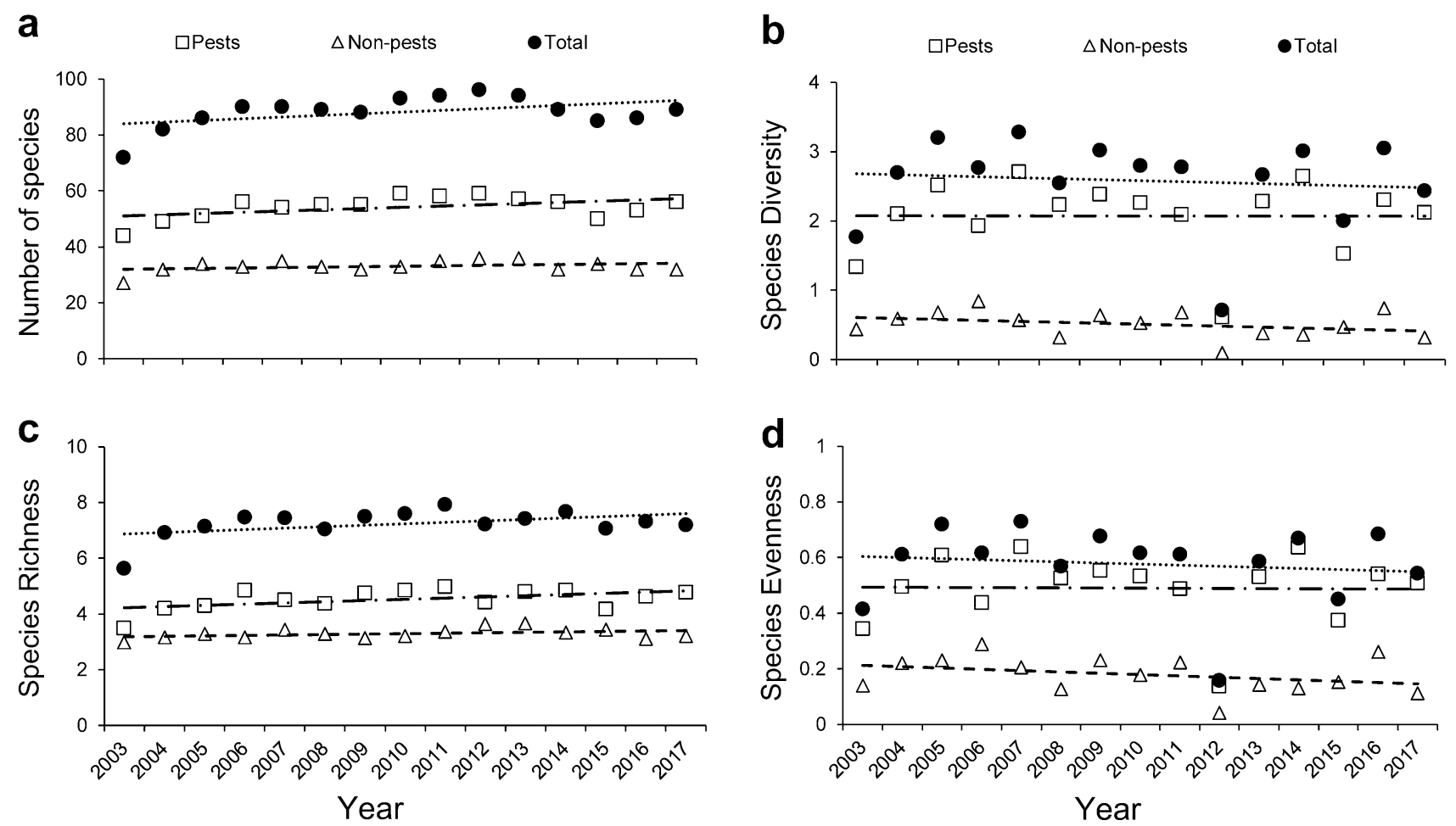

Fig. 3 Annual variation in the number of species (a), species diversity (b), species richness (c), and species evenness (d) during 2003-2017. Linear regression model (dashed line): a pests, $y=0.439 x+50.619, \quad R^{2}=0.23, \quad$ non-pests, $\quad y=0.154 x+31.84$, $R^{2}=0.10, \quad$ total, $\quad y=0.593 x+83.457, \quad R^{2}=0.20 ; \quad$ b pests, $y=-0.001 x+2.075, \quad R^{2}=0.01, \quad$ non-pests, $\quad y=-0.014 x+0.622$,

correlated with those of their natural enemies (linear model, $\left.y=1.251 x-2.031 ; R^{2}=0.89, F_{1,13}=39.94, P=0.001\right)$ (Fig. 6a). Yet, with increasing (annual aggregate) abundance of natural enemies, we recorded a lower aggregate abundance of noctuid pests (linear model, $y=-0.447 x+6.148$; $\left.R^{2}=0.34, F_{1,13}=6.79, P=0.02\right)$ (Fig. 6b).

\section{Discussion}

In eastern Asia, meteorological conditions and host plant availability create suitable conditions for the long-distance migration of at least 119 insect species, comprising 36 families and 9 orders. Our 15-year systematic monitoring of these migratory insect populations revealed how agriculturally subsidized (polyphagous) pest species make up the bulk of trap capture records. More specifically, all seven most abundant species (representing $54 \%$ of total abundance) were crop-feeding noctuids of immediate relevance in China's agriculture, while the 30 species of agriculturally important noctuids comprised $63 \%$ of total abundance. Many of the trapped species immigrate annually from subtropical and warm temperate zones, as revealed by pollen

$R^{2}=0.10, \quad$ total, $\quad y=-0.014 x+2.697, \quad R^{2}=0.01 ; \quad$ c pests, $y=0.043 x+4.183, R^{2}=0.25$, non-pests, $y=0.016 x+3.170, R^{2}=0.13$, total, $y=0.052 x+6.823, R^{2}=0.20 ; \quad$ d pests, $y=-0.001 x+0.494$, $R^{2}=0.01, \quad$ non-pests, $\quad y=-0.005 x+0.217, \quad R^{2}=0.10, \quad$ total, $y=-0.004 x+0.608, R^{2}=0.01 . y$ represents the annual response variable; $x$ represents the order value of the year (e.g., $x=1$ in 2003)

grain identification, stable isotope measurement and trajectory analysis (Chang et al. 2018; Cao et al. 2018). Our data illuminate the pronounced seasonal and inter-annual 'upand-down' fluctuations in the abundance of a subset of agriculturally subsidized taxa (Macgregor et al. 2019), reveal how natural enemies migrate alongside noctuid pests, and accentuate how sustained losses in non-pest species might eventually compromise strength and stability of insect-mediated ecosystem services, e.g., biological control.

Our observation of $>2.5$ million migratory insects from myriad taxonomic groups is not exceptional (Russell et al. 1998; Holland et al. 2006; Chapman and Drake 2010; Chapman et al. 2015). For example, 115 insect taxa from 12 different orders can be trapped on the remote Willis Island off northeastern Australia (Farrow 1984), while a staggering 3.5 trillion insects are thought to migrate annually over the southern UK (Hu et al. 2016). Such large-scale migration of multiple insect species hints at the possibility of co-evolution between functional groups, e.g., co-migrating noctuid herbivores and predatory beetles.

Species-specific (and overall) migration dynamics exhibit marked seasonal fluctuations that are potentially linked to meteorological conditions and host plant phenology 

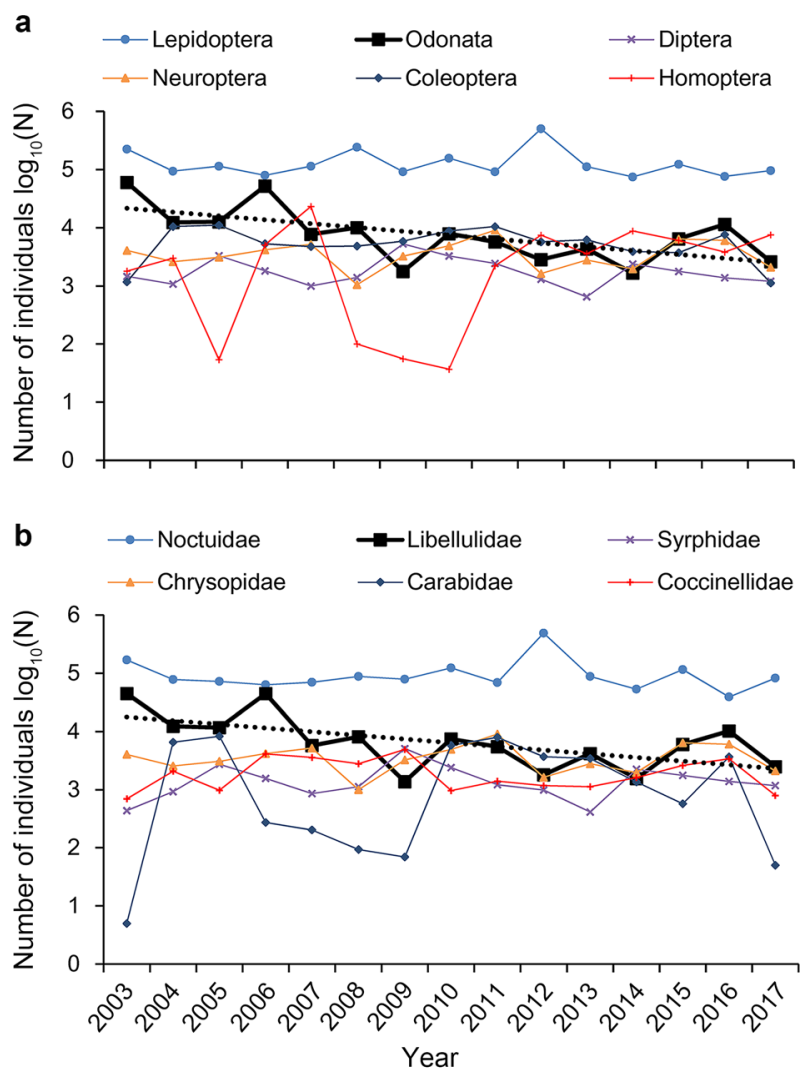

Fig. 4 Annual variation in the number of individuals in different orders (a) and families (b) during 2003-2017. Economically important orders and families with the total trap catches $>20,000$ over the 15 -year window, mainly including pests and natural enemies, are shown in the graph. Only Odonata and Libellulidae exhibit a significant downward trend in the number of individuals, linear model (dashed line): $y=-0.066 x+4.398, R^{2}=0.41, y=-0.063 x+4.311$, $R^{2}=0.38$, respectively. No significant upward or downward trend in the number of individuals is recorded in any other insect orders and families

(Chapman et al. 2015; Suyjayanand and Karuppaiah 2016). Similar patterns have been recorded for various species of agriculturally important Lepidoptera and Hemiptera (Feng et al. 2008, 2009; Fu et al. 2014, 2015). Meanwhile, trap capture rates exhibited substantial inter-annual variation, with species-level abundance and occurrence on BH likely to be strongly correlated to annual abundance patterns in mainland China. For example, trap capture rates of the oriental armyworm M. separata on BH were high during 2012, at times when this pest attained outbreak levels in China's extensive corn crop (Zhang et al. 2012).

In Europe and North America, a compelling body of evidence has accumulated on how multiple insect taxa (i.e., butterflies, moths, leafhoppers) are experiencing near-precipitous population declines (Diamond 1989; Maes and Dyck 2001; Conrad et al. 2006; Shortall et al. 2009; Schuch et al. 2012; Melero et al. 2016; Hallmann et al. 2017; Sánchez-Bayo and Wyckhuys 2019; Seibold et al. 2019). Yet, in our study, $79 \%$ of migrating species did not exhibit any consistent directional trend in annual abundance. Given their superior dispersal ability and (often) large body size, migratory species possibly cope better with unfavorable environmental conditions such as habitat loss, land-use change, and environmental pollution (Butchart et al. 2010; Chen et al. 2011; Melero et al. 2016). Global warming can also benefit abundance and spatial distribution of certain species in temperate regions (Deutsch et al. 2008), while wind alters migrant colonization patterns and possibly distorts year-to-year monitoring data (Drake and Farrow 1988; Pair and Westbrook 1995). Lastly, given the large variability in annual abundance of most species, our monitoring period could have been too short to detect meaningful long-term patterns. Hence, the relatively stable population sizes of most migrant insects at our BH island site are not necessarily comparable with the observed declines among (small-sized, flightless or short-distance dispersing) insects in mainland settings.

Yet, approximately $17.6 \%$ of caught species at $\mathrm{BH}$, including crop pests (e.g., A. ipsilon, C. agnata) and key natural enemies such as the skimmer $P$. flavescens or the carabid beetle Calosoma maderae Kirby, do exhibit unmistakable population declines-similar to those observed among macro-months in Britain or dragonflies in Japan (Conrad et al. 2006; Kadoya et al. 2009). By assessing temporal shifts in abundance instead of biomass (Macgregor et al. 2019), we also gain a more reliable measure of the fate of individual species and avoid data from being unnecessarily skewed by the trapping records of few large-bodied (crop-feeding) species. Population trends of particular species are further affected by their respective ecological and life-history traits (Melero et al. 2016), with multivoltine insect species experiencing steeper population declines than uni- or bivoltine ones (Börschig et al. 2013). Also, moths and dragonflies are highly sensitive to changes in ecological parameters and environmental quality (Erhardt and Thomas 1991; Hawking and New 2002; Kadoya et al. 2004). Their declining abundance can thus be ascribed to multiple factors, including human-driven land-use change, agro-chemical pollution, and global warming (Wilcove et al. 1998; Conrad et al. 2006; Hahn et al. 2015; Sánchez-Bayo and Wyckhuys 2019). The decline rate (14\% per year, approx. $90 \%$ decline over the entire 15-year period) in abundance for the entire order of Odonata is of considerable concern and is plausibly related to an increased use of systemic insecticides in Asian paddy rice (Nakanishi et al. 2018). The latter can signal a gradual breakdown of biological control mechanisms in aquatic settings and possibly compromise an effective regulation of crop pests (e.g., rice planthoppers or snails; Kiritani 2000) or nuisance mosquitoes. 
Table 1 Temporal trends in species-level abundance for 22 migratory insect species, over a 15-year time window

\begin{tabular}{|c|c|c|c|c|c|c|}
\hline No. & Species & Annual catches $($ mean $\pm S E)$ & Range & $r_{s}^{*}$ & $P$ & Taxa \\
\hline & Lepidoptera: Noctuidae & & & & & \\
\hline 1 & Agrotis ipsilon (Hufnagel) & $4711.53 \pm 706.62$ & $1079-10,535$ & -0.71 & 0.003 & $\Delta$ \\
\hline 2 & Agrotis tokionis Butler & $329.46 \pm 64.31$ & $5-707$ & 0.67 & 0.012 & $\Delta$ \\
\hline 3 & Ctenoplusia agnata (Staudinger) & $9832.6 \pm 3479.06$ & $842-46,787$ & -0.73 & 0.002 & $\Delta$ \\
\hline 4 & Chrysorithrum amata (Bremer) & $128.6 \pm 22.37$ & $28-318$ & -0.63 & 0.011 & $\Delta$ \\
\hline 5 & Acronicta rumicis Linnaeus & $186.92 \pm 66.61$ & $0-689$ & -0.76 & 0.003 & $\Delta$ \\
\hline 6 & Anomis flava (Fabricius) & $180.87 \pm 55.71$ & $0-751$ & -0.76 & 0.001 & $\Delta$ \\
\hline \multirow[t]{2}{*}{7} & Ascotis selenaria (Schiffermuller et Denis) & $149.57 \pm 46.58$ & $0-517$ & -0.77 & 0.001 & $\Delta$ \\
\hline & Lepidoptera: Geometridae & & & & & \\
\hline \multirow[t]{2}{*}{8} & Calothysanis comptaria Walker & $687.50 \pm 202.29$ & $9-2140$ & -0.68 & 0.008 & $\Delta$ \\
\hline & Lepidoptera: Arctiidae & & & & & \\
\hline \multirow[t]{2}{*}{9} & Spilosoma niveus (Ménétriés) & $287.86 \pm 72.61$ & $4-1023$ & -0.88 & $<0.001$ & $\Delta$ \\
\hline & Lepidoptera: Sphingidae & & & & & \\
\hline 10 & Parum colligate (Walker) & $63.14 \pm 8.61$ & $22-142$ & -0.92 & $<0.001$ & $\diamond$ \\
\hline \multirow[t]{2}{*}{11} & Callambulyx tartarunovii Bremer et Grey & $45.64 \pm 9.52$ & $5-105$ & -0.67 & 0.009 & $\diamond$ \\
\hline & Lepidoptera: Pyralididae & & & & & \\
\hline 12 & Conogethes punctiferalis Guenée & $1205.33 \pm 520.79$ & $129-8286$ & 0.55 & 0.034 & $\Delta$ \\
\hline 13 & Diaphanaia indica (Saunders) & $607.87 \pm 186.23$ & $15-2909$ & -0.70 & 0.003 & $\Delta$ \\
\hline \multirow[t]{2}{*}{14} & Cnaphalocrocis medinalis Guenée & $6404.87 \pm 3138.36$ & $118-49,187$ & -0.79 & 0.001 & $\Delta$ \\
\hline & Hemiptera: Miridae & & & & & \\
\hline \multirow[t]{2}{*}{15} & Apolygus lucorum (Meyer-Dür) & $288.27 \pm 75.30$ & $0-774$ & 0.86 & $<0.001$ & $\Delta$ \\
\hline & Hemiptera: Pentatomidae & & & & & \\
\hline \multirow[t]{2}{*}{16} & Halyomorpha picus Fabricius & $344.88 \pm 153.39$ & $0-1207$ & -0.95 & $<0.001$ & $\triangle$ \\
\hline & Odonata: Libellulidae & & & & & \\
\hline \multirow[t]{2}{*}{17} & Pantala flavescens Fabricius & $12098.33 \pm 3606.57$ & $1364-59,342$ & -0.61 & 0.015 & $\diamond$ \\
\hline & Coleoptera: Carabidae & & & & & \\
\hline 18 & Calosoma maderae chinense Kirby & $166.57 \pm 143.95$ & $0-2035$ & -0.79 & 0.001 & $\diamond$ \\
\hline \multirow[t]{2}{*}{19} & Chlaenius micans Fabricius & $442.2 \pm 413.07$ & $0-6220$ & -0.55 & 0.034 & $\diamond$ \\
\hline & Coleoptera: Coccinellidae & & & & & \\
\hline \multirow[t]{2}{*}{20} & Propylea japonica (Thunberg) & $636 \pm 200.24$ & $7-2560$ & -0.61 & 0.020 & $\diamond$ \\
\hline & Coleoptera: Melolonthidae & & & & & \\
\hline \multirow[t]{2}{*}{21} & Holotrichia diomphalia Bates & $102.47 \pm 85.50$ & $0-1296$ & -0.55 & 0.034 & $\Delta$ \\
\hline & Coleoptera: Scarabaeoidae & & & & & \\
\hline 22 & Anomala exoleta Faldermann & $254.64 \pm 85.14$ & $0-1045$ & -0.55 & 0.040 & $\Delta$ \\
\hline
\end{tabular}

Patterns are shown for a subset of 22 insect species that exhibit a statistically significant directional trend in abundance over time

$* r_{s}$ is the Spearman's correlation coefficient, with negative values (bold) representing downward and positive values representing upward trend. Due to non-normality of raw and transformed data, annual decline rate was not analyzed. $\Delta=$ pest, including both multiple agricultural and few forestry pest species, $\diamond=$ non-pest, including insect natural enemies, 'neutral species' and species of limited economic importance (to agriculture and forestry)

Conversely, population levels of certain crop pests, e.g., the polyphagous mirid A. lucorum, exhibited an upward trend. This probably can be ascribed to its population resurgence following reductions in insecticide use in China's genetically modified Bt cotton crop (Wu and Guo 2005) and to field-evolved resistance to multiple common insecticides in other agro-ecosystems (Zhang et al. 2015). In instances where biocide-resistance triggers insect population increase, sustained (or enhanced) biological control is especially important. Yet, as the exact drivers of decline (or population increase) undoubtedly vary from species to species, followup research is warranted though should not obstruct a timely deployment of appropriate mitigation measures (SánchezBayo and Wyckhuys 2019).

Natural enemies (e.g., ladybirds, lacewings, dragonflies) provide biological control services in both natural and manmade environments; their active in-field conservation is a core element of integrated pest management (IPM) (Landis et al. 2000; Losey and Vaughan 2006; Huang et al. 2018). The relative contribution of natural enemies to pest control 


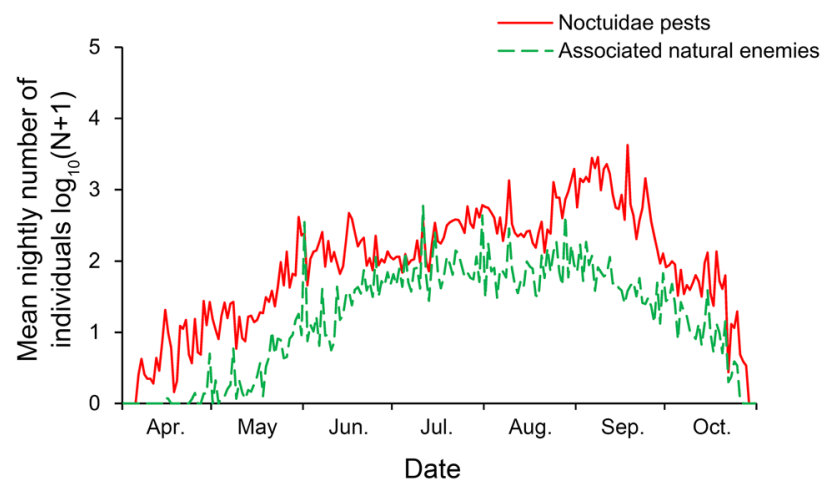

Fig. 5 Nightly abundance of noctuid pests and associated natural enemies captured in a searchlight trap on BH from April to October, as averaged over a 15 -year period
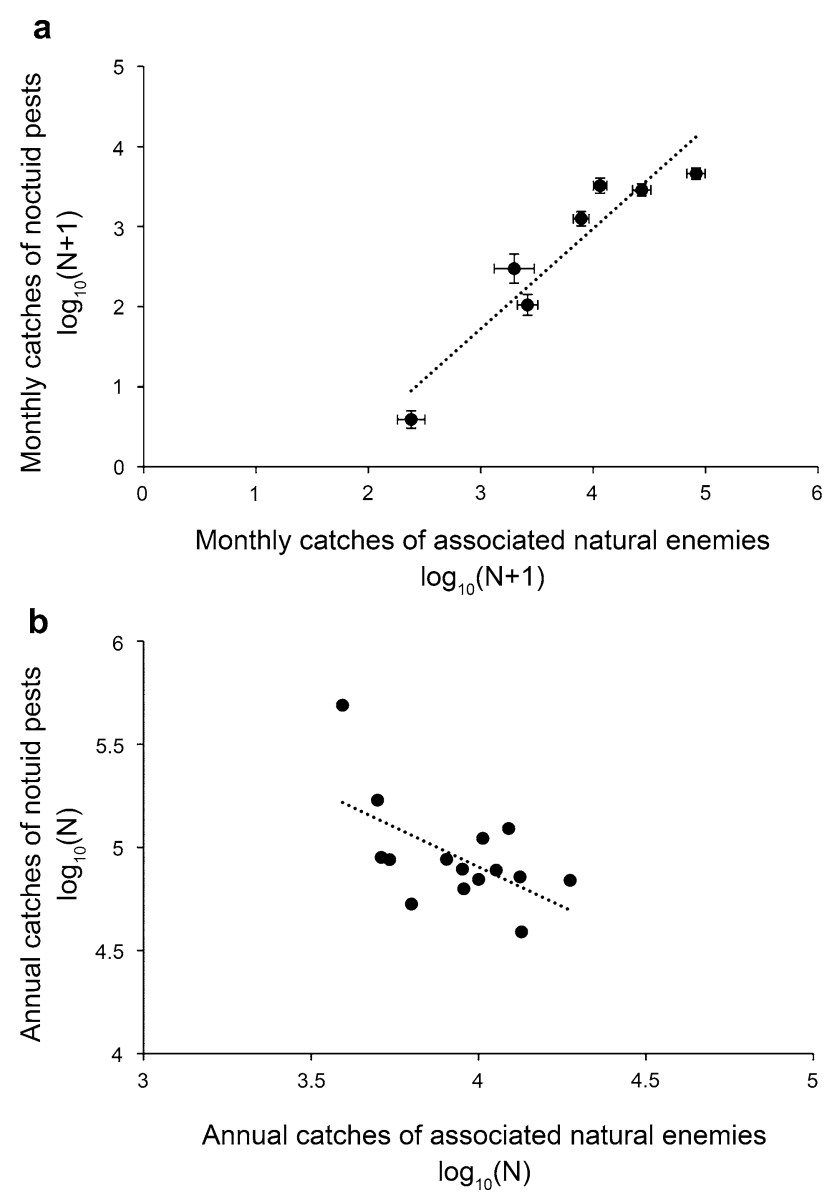

Fig. 6 Linear regression of monthly (a) and annual abundance (b) of noctuid pests versus their associated natural enemies during 20032017. Linear regression model is used to assess monthly and annual patterns for 30 different species of noctuid pests and their associated natural enemies (5 families, 14 different species). Dashed line: a $y=1.251 x-2.031, R^{2}=0.89 ; \mathbf{b} y=-0.447 x+6.148, R^{2}=0.34$ hinges upon a synchronous colonization of either functional group in a given field or agro-landscape (Welch and Harwood 2014) and is further shaped by natural enemy traits and habitat type (Wiedenmann and Smith 1997). Here, we reveal how natural enemies engage in long-distance migration in tandem with agricultural pest populations from April to October, as noted earlier for predators and parasitoids of various homopteran pests [e.g., Aphidus avenae Haliday and Sitobion avenae (Fabricius), Cyrtorhinus lividipennis Reute and Nilaparvata lugens (Stål)] (Mochida and Takada 1978; Luo et al. 1994; Zhai 2001). Coupled (high-altitude) migration of both guilds may facilitate concurrent colonization of agro-landscapes and thus benefit biological control, though this needs to be confirmed empirically. Furthermore, we show how the annual abundance of natural enemies negatively relates to that of migrant noctuids-potentially indicating their suppressive action on lepidopteran pest populations (Zhai 2001). Lastly, the lagged migration of natural enemies (Qi 2014) can signal an evolutionary adaptation through which prior establishment of noctuids provides sufficient food resources and guarantees the establishment of natural enemy colonists.

Overall, our work unveils long-distance migration of multiple insect species and a coupled migration of locally important crop pests and natural enemies. Furthermore, we record how $18 \%$ of (large-bodied, flying) migratory species experience a progressively declining abundance and how seasonal dynamics of agriculturally subsidized pests can obscure those of less-abundant beneficial species. Offering unprecedented insights into the multi-year dynamics and species-level specificities of local insect migration, our work underpins the development of monitoring and forecasting systems for both pests and biological control agents. Followup research eventually combined with pollen analyses and entomological radar monitoring can delineate migration trajectories of economically important species such as the newly invasive $S$. frugiperda (Hendrix and Showers 1992; Drake and Reynolds 2012; Stokstad 2017), ascertain the relative contribution of meteorological parameters (Suyjayanand and Karuppiah 2016), and assess adaptations of certain migrant species (Johnson 1969; Langellotto and Ott 2000). This work can ultimately shed light on the fate of certain functional guilds (e.g., insect-killing Odonata) and their associated biological control services and thereby help build resilience against crop pests and nuisance organisms at a macroscale.

\section{Author contributions}

KW conceived and designed research. JG, XF, SZ, and XS conducted the experiments. JG analyzed the data. JG wrote the first draft of the manuscript. The manuscript was 
revisited and edited by KM and KAGW. All the authors read and approved the manuscript.

Acknowledgements We thank Doudou Wang, Long Cao, and Xiaodong Cai from the College of Plant Protection, Henan Agricultural University, for their contributions in insect collecting. This research was supported by the National Natural Sciences Foundation of China (31621064 and 31727901).

\section{Compliance with ethical standards}

Conflict of interest The authors declare that they have no conflict of interest.

Human and animals This article does not contain any studies with human participants or animals (vertebrates).

Open Access This article is licensed under a Creative Commons Attribution 4.0 International License, which permits use, sharing, adaptation, distribution and reproduction in any medium or format, as long as you give appropriate credit to the original author(s) and the source, provide a link to the Creative Commons licence, and indicate if changes were made. The images or other third party material in this article are included in the article's Creative Commons licence, unless indicated otherwise in a credit line to the material. If material is not included in the article's Creative Commons licence and your intended use is not permitted by statutory regulation or exceeds the permitted use, you will need to obtain permission directly from the copyright holder. To view a copy of this licence, visit http://creativecommons.org/licenses/by/4.0/.

\section{References}

Bauer S, Hoye BJ (2014) Migratory animals couple biodiversity and ecosystem functioning worldwide. Science 344:1242552

Börschig C, Klein AM, Von Wehrden H, Krauss J (2013) Traits of butterfly communities change from specialist to generalist characteristics with increasing land-use intensity. Basic Appl Ecol 14:547-554

Butchart SHM, Walpole M, Collen B et al (2010) Global biodiversity: indicators of recent declines. Science 328:1164-1168

Cao LZ, Fu XW, Hu CX, Wu KM (2018) Seasonal migration of Pantala flavesces across the Bohai Strait in northern China. Environ Entomol 20:1-7

Chang H, Guo JL, Fu XW, Liu YQ, Wyckhuys KAG, Hou YM, Wu KM (2018) Molecular-assisted pollen grain analysis reveals spatiotemporal origin of long-distance migrants of a noctuid moth. Int J Mol Sci 19:567-581

Chapman JW, Drake VA (2010) Insect migration. In: Breed MD, Moore J (eds) Encyclopedia of animal behavior. Academic Press, Oxford, pp 161-166

Chapman JW, Klaassen RHG, Drake VA, Fossette S, Hays GC, Metcalfe JD, Reynolds AM, Reynolds DR, Alerstam T (2011) Animal orientation strategies for movement in flows. Curr Biol 21:861-870

Chapman JW, Reynolds DR, Wilson K (2015) Long-range seasonal migration in insects: mechanisms, evolutionary drivers and ecological consequences. Ecol Lett 18:287-302

Chen RL, Bao XZ, Drake VA, Farrow RA, Wang SY, Sun YJ, Zhai BP (1989) Radar observations of the spring migration into northeastern China of the oriental armyworm moth, Mythimna separata, and other insects. Ecol Entomol 14:149-162
Chen IC, Hill JK, Shiu HJ, Holloway JD, Benedick S, Chey VK, Barlow HS, Thomas CD (2011) Asymmetric boundary shifts of tropical montane Lepidoptera over four decades of climate warming. Glob Ecol Biogeogr 20:34-45

Cheng SN, Chen JC, Si H, Yan LM, Chu TL, Wu CT, Chen JK, Yan CS (1979) Studies on the migrations of brown planthopper, Nilaparvata lugens Stål. Acta Entomol Sin 22:1-21 (in Chinese)

Conrad KF, Warren MS, Fox R, Parsons MS, Woiwod IP (2006) Rapid declines of common, widespread British moths provide evidence of an insect biodiversity crises. Biol Conserv 132:279-291

Deutsch CA, Tewksbury JJ, Huey RB, Sheldon KS, Ghalambor CK, Haak DC, Martin PR (2008) Impacts of climate warming on terrestrial ectotherms across latitude. Proc Natl Acad Sci 105:6668-6672

Diamond JM (1989) The present, past and future of human-caused extinctions. Philos Trans R Soc Lond Ser B Biol Sci 325:469-477

Dingle H, Drake VA (2007) What is migration? Bioscience 57:113-121

Drake VA, Farrow RA (1988) The influence of atmospheric structure and motions on insect migration. Annu Rev Entomol 33:183-210

Drake VA, Gatehouse AG (1995) Insect migration: tracking resources through space and time. Cambridge University Press, Melbourne

Drake VA, Reynolds DR (2012) Radar entomology: observing insect flight and migration. CABI, Wallingford

Early R, Gonzalez-Moreno P, Murphy ST, Day R (2018) Forecasting the global extent of invasion of the cereal pest Spodoptera frugiperda, the fall armyworm. NeoBiota 40:25-50

Erhardt A, Thomas JA (1991) Lepidoptera as indicators of change in semi-natural grasslands of lowland and upland in Europe. In: Collins NM, Thomas J (eds) The conservation of insects and their habitats. Academic Press, London, pp 213-236

Farrow RA (1984) Detection of transoceanic migration of insects to a remote island in the Coral Sea, Willis Island. Aust J Ecol 9:253-272

Feng HQ, Wu KM, Cheng DF, Guo YY (2003) Radar observations of the autumn migration of the beet armyworm Spodoptera exigua (Lepidoptera: Noctuidae) and other moths in northern China. Bull Entomol Res 93:115-124

Feng HQ, Wu KM, Ni YX, Cheng DF, Guo YY (2006) Nocturnal migration of dragonflies over the Bohai Sea in northern China. Ecol Entomol 31:511-520

Feng HQ, Zhao XC, Wu XF, Wu B, Wu KM, Cheng DF, Guo YY (2008) Autumn migration of Mythimna separata (Lepidoptera: Noctuidae) over the Bohai Sea in northern China. Environ Entomol 37:774-781

Feng HQ, Wu XF, Wu B, Wu KM (2009) Seasonal migration of Helicoverpa armigera (Lepidoptera: Noctuidae) over the Bohai Sea. J Econ Entomol 102:95-104

Flockhart DTT, Wassenaar LI, Martin TG, Hobson KA, Wunder MB, Norris DR (2013) Tracking multi-generational colonization of the breeding grounds by monarch butterflies in eastern North America. Proc R Soc B-Biol Sci 280:20131087

Fu XW, Liu YQ, Li C, Lu YH, Li YH, Wu KM (2014) Seasonal migration of Apolygus lucorum (Hemiptera: Miridae) over the Bohai Sea in northern China. J Econ Entomol 107:1399-1410

Fu XW, Zhao XY, Xie BT, Ali A, Wu KM (2015) Seasonal pattern of Spodoptera litura (Lepidoptera: Noctuidae) migration across the Bohai Strait in northern China. J Econ Entomol 108:525-538

Fu XW, Feng HQ, Liu ZF, Wu KM (2017) Trans-regional migration of the beet armyworm, Spodoptera exigua (Lepidoptera: Noctuidae), in North-East Asia. PLoS ONE 12:e0183582

Hahn M, Schotthöfer A, Schmitz J, Franke LA, Brühl CA (2015) The effects of agrochemicals on Lepidoptera, with a focus on moths, and their pollination service in field margin habitats. Agric Ecosyst Environ 207:153-162

Hallmann CA, Sorg M, Jongejans E, Siepel H, Hofland N, Schwan H, Stenmans W, Müller A, Sumser H, Hörren T, Goulson D (2017) 
More than 75 percent decline over 27 years in total flying insect biomass in protected areas. PLoS ONE 12:e0185809

Hallworth MT, Marra P, McFarland KP, Zahendra S, Studds CE (2018) Tracking dragons: stable isotopes reveal the annual cycle of a long-distance migratory insect. Biol Lett 14:1-5

Hawking JH, New TR (2002) Interpreting dragonfly diversity to aid in conservation assessment: lessons from the Odonata assemblage at Middle Creek, north-eastern Victoria, Australia. J Insect Conserv 6:171-178

Hendrix WH, Showers WB (1992) Tracing black cutworm and armyworm (Lepidoptera: Noctuidae) northward migration using Pithecellobium and Calliandra pollen. Environ Entomol 21:1092-1096

Hobson KA, Charles AR, Soto DX, Wassenaar LI (2012) Isotopic evidence that dragonflies (Pantala flavescens) migrating through the Maldives Come from the northern Indian subcontinent. PLoS ONE 7:e52594

Holland RA, Wikelski M, Wilcove DS (2006) How and why do insects migrate? Science 313:794-796

Hu G, Lim KS, Horvita N, Clark SJ, Reynolds DR, Sapir N, Chapman JW (2016) Mass seasonal bioflows of high-flying insect migrants. Science 354:1584-1587

Huang JK, Zhou K, Zhang W, Deng XZ, Werf WVD, Lu YH, Wu KM, Rosegrant MW (2018) Uncovering the economic value of natural enemies and true costs of chemical insecticides to cotton farmers in China. Environ Res Lett. https://doi. org/10.1088/1748-9326/aabfb0

IBM Corporation (2011) IBM SPSS Statistics for Windows, version 20.0. IBM Corporation, Armonk, USA

Johnson CG (1969) Migration and dispersal of insects by flight. Metheun and Co, London

Kadoya T, Suda SI, Washitani I (2004) Dragonfly species richness on man-made ponds: effects of pond size and pond age on newly established assemblages. Ecol Res 19:461-467

Kadoya T, Suda SI, Washitani I (2009) Dragonfly crisis in Japan: a likely consequence of recent agricultural habitat degradation. Biol Conserv 142:1899-1905

Kiritani K (2000) Integrated biodiversity management in paddy fields: shift of paradigm from IPM toward IBM. Integr Pest Manag Rev 5:175-183

Kisimoto R (1981) Development, behavior, population dynamics and control of the brown planthopper, Nilaparvata lugens Stål. Rew Plant Prot Res 14:26-58

Landis DA, Wratten SD, Gurr GM (2000) Habitat management to conserve natural enemies of arthropod pests in agriculture. Annu Rev Entomol 45:175-201

Landry J, Parrott L, Peters DPC (2016) Could the lateral transfer of nutrients by outbreaking insects lead to consequential landscape-scale effects? Ecosphere 7:e01265

Langellotto GA, Ott DJR (2000) A trade-off between flight capability and reproduction in males of a wing-dimorphic insect. Ecology 81:865-875

Li CZ, Luo ZY (1979) Agricultural insects one hundred identification album. Science and Technology Press, Shanghai (in Chinese)

Liu YQ, Fu XW, Mao LM, Xing ZL, Wu KM (2016) Host plants identification for adult Agrotis ipsilon, a long-distance migratory insect. Int J Mol Sci 17:851-863

Losey JE, Vaughan M (2006) The economic value of ecological services provided by insects. Bioscience 56:311-323

Luo RW, Yang CL, Shang YF, Li CS, Zhao JH (1994) Studies on the population dynamics and aphid control capability of Aphidius avenae. Acta Phytophylacica Sin 21:163-168 (in Chinese)

Macgregor CJ, Williams JH, Bell JR, Thomas CD (2019) Moth biomass increases and decreases over 50 years in Britain. Nat Ecol Evol 3:1645-1649
Maes D, Dyck HV (2001) Butterfly diversity loss in Flanders (north Belgium): Europe's worst case scenario? Biol Conserv 99:263-276

Melero Y, Stefanescu C, Pino J (2016) General declines in Mediterranean butterflies over the last two decades are modulated by species traits. Biol Conserv 201:336-342

Mochida O, Takada H (1978) Possible migration of aphid parasites (Hymenoptera: Aphidiidae) across the East China Sea. Appl Entomol Zool 13:125-127

Mouritsen H, Frost BJ (2002) Virtual migration in tethered flying monarch butterflies reveals their orientation mechanisms. Proc Natl Acad Sci 99:10162-10166

Nakanishi K, Yokomizo H, Hayashi TI (2018) Were the sharp declines of dragonfly populations in the 1990s in Japan caused by fipronil and imidacloprid? An analysis of Hill's causality for the case of Sympetrum frequens. Environ Sci Pollut Res 25:35352-35364

Pair SD, Westbrook JK (1995) Agroecological and climatological factors potentially influencing armyworm Lepidoptera, Noctuidae populations and their movement in the southeastern United States. Southwest Entomol 18:101-118

Pielou E (1966) Shannon's formula as a measure of specific diversity: its use and misuse. Am Nat 100:463-465

Qi HH (2014) Study on migration of rice two migration pests and population dynamics of important natural enemies in Xiang-gui Corridor. Dissertation, Chinese Academy of Agricultural Sciences (in Chinese)

Relyea RA, Hoverman JT (2008) Interactive effects of predators and a pesticide on aquatic communities. Oikos 117:1647-1658

Reynolds DR, Chapman JW, Harrington R (2006) The migration of insect vectors of plant and animal viruses. Adv Virus Res 67:453-517

Russell RW, May ML, Soltesz KL, Fitzpatrick JW (1998) Massive swarm migrations of dragonflies (Odonata) in Eastern North America. Am Midl Nat 140:325-342

Rutter JF, Mills AP, Rosenberg LJ (1998) Weather associated with autumn and winter migrations of rice pests and other insects in south-eastern and eastern Asia. Bull Entomol Res 88:189-197

Sánchez-Bayo F, Wyckhuys KA (2019) Worldwide decline of the entomofauna: a review of its drivers. Biol Conserv 232:8-27

Schaefer PW, Dysart RJ, Specht HB (1987) North American distribution of Coccinella septempunctata (Coleoptera: Coccinellidae) and its mass appearance in coastal Delaware. Environ Entomol 16:368-373

Schuch S, Wesche K, Schaefer M (2012) Long-term decline in the abundance of leafhoppers and planthoppers (Auchenorrhyncha) in central European protected dry grasslands. Biol Conserv 149:75-83

Seibold S, Gossner MM, Simons NK, Blüthgen N, Müller J, Ambarlı D, Ammer C, Bauhus J, Fischer M, Habel JC, Linsenmair KE, Nauss T, Penone C, Prati D, Schall P, Schulze ED, Vogt J, Wöllauer S, Weisser WW (2019) Arthropod decline in grasslands and forests is associated with landscape-level drivers. Nature 574:671-674

Serafim JM, Lansac-Tôha FA, Paggi JC, Velho LFM, Robertson B (2003) Cladocera fauna composition in a river-lagoon system of the upper paraná river floodplain, with a new record for Brazil. Braz J Biol 2:349-356

Shortall CR, Moore A, Smith E, Hall MJ, Woiwod IP, Harrington $\mathrm{R}$ (2009) Long-term changes in the abundance of flying insect. Insect Conserv Divers 2:251-260

Southwood TRE (1977) Habitat, the templet for ecological strategies? J Anim Ecol 46:337-365

Stefanescu C, Páramo F, Åkesson S, Alarcón M, Ávila A, Brereton T et al (2013) Multi-generational long-distance migration in insects: studying the painted lady butterfly in the Western Palaearctic. Ecography 36:474-486 
Stefanescu C, Puig-Montserrat X, Samraoui B, Izquierdo R, Ubach A, Arrizabalaga A (2017) Back to Africa: autumn migration of the painted lady butterfly Vanessa cardui is timed to coincide with an increase in resource availability. Ecol Entomol 42:737-747

Stokstad E (2017) New crop pest takes Africa at lightning speed. Science 356:473-474

Suyjayanand GK, Karuppiah V (2016) Aftermath of climate change on insect migration: a review. Agric Rev 37:221-227

Talavera G, Vila R (2016) Discovery of mass migration and breeding of the painted lady butterfly Vanessa cardui in the Sub-Sahara: the Europe-Africa migration revisited. Biol J Linn Soc 120:274-285

Vreysen MJB, Robinson AS, Hendrichs J (2007) Area-wide control of insect pests: from research to field implementation. Springer, Heidelberg

Welch KD, Harwood JD (2014) Temporal dynamics of natural enemy-pest interactions in a changing environment. Biol Control 75:18-27

Wiedenmann RN, Smith JW (1997) Attributes of natural enemies in ephemeral crop habitats. Biol Control 10:16-22

Wilcove DS, Rothstein D, Dubow J, Phillips A, Losos E (1998) Quantifying threats to imperiled species in the United States. Bioscience 48:607-615

Wu KM, Guo YY (2005) The evolution of cotton pest management practices in China. Annu Rev Entomol 50:31-52

Yang JK (1978) Moths under the lights in North China (II). Beijing Agricultural University Press, Beijing (in Chinese)

Zhai BP (2001) Accompany migration of natural enemies and biodiversity. Biodivers Sci 9:176-180 (in Chinese)

Zhang XM, Li Q, Chen GH, Yang J, Gao X, Song JX (2009) Insect community structure and its stability in Zanthoxylum bungeanum garden with different planting pattern. Chin J Appl Entomol 20:1986-1991

Zhang YH, Zhang Z, Jiang YY, Zeng J, Gao YB, Cheng DF (2012) Preliminary analysis of the outbreak of the third-generation armyworm Mythimna separata in China in 2012. Plant Prot 38:1-8 (in Chinese)

Zhang P, Zhao YH, Zhang XF, Song YY, Zhang ZQ, Liu F (2015) Field resistance monitoring of Apolygus lucorum (Hemiptera: Miridae) in Shandong, China to seven commonly used insecticides. Crop Prot 76:127-133

Zhang XT, Pan XB, Xu L, Wei P, Hu Q, Yin ZW, Shao CX (2017) Spatio-temporal variation of agricultural thermal resources at different critical temperatures in China's temperate zone. Resour Sci 39:2104-2115 (in Chinese)

Zhou Y (2001) Zhou Yao insect atlas. Henan Science and Technology Press, Zhengzhou (in Chinese)

Zhu HF, Liu YQ, Bai JW (1981) Chinese moth illustration (I). Science Press, Beijing (in Chinese)

Zhu HF, Liu YQ, Bai JW (1982a) Chinese moth illustration (II). Science Press, Beijing (in Chinese)

Zhu HF, Liu YQ, Bai JW (1982b) Chinese moth illustration (III). Science Press, Beijing (in Chinese)

Publisher's Note Springer Nature remains neutral with regard to jurisdictional claims in published maps and institutional affiliations. 